\title{
CRESCIMENTO INICIAL DO PINHÃO-MANSO SUBMETIDO A DIFERENTES REGIMES HÍDRICOS EM LATOSSOLO VERMELHO DISTRÓFICO
}

\author{
INITIAL GROWTH OF PHYSIC NUT SUBMITTED TO DIFFERENT WATER REGIMES IN \\ DYSTROPHIC HAPLUSTOX
}

\begin{abstract}
Neriane de Souza Padilha ${ }^{1}$ Cesar José da Silva ${ }^{2}$ Silvio Bueno Pereira ${ }^{3}$ João Alfredo Neto da Silva ${ }^{4}$ Débora Menani Heid ${ }^{1}$ Simone Priscila Bottega ${ }^{1}$ Silvana de Paula Quintão Scalon ${ }^{5}$
\end{abstract}

\begin{abstract}
RESUMO
O objetivo deste trabalho foi avaliar o crescimento inicial e algumas variáveis fisiológicas de pinhãomanso (Jatropha curcas L.) submetido a diferentes regimes hídricos em Latossolo Vermelho distrófico. O experimento foi conduzido em casa de vegetação da Embrapa Agropecuária Oeste, em Dourados-MS. Os tratamentos corresponderam aos regimes hídricos de 20,40,60, 80 e 100\% da capacidade de retenção de água no solo. O delineamento experimental adotado foi o inteiramente casualizado com cinco regimes hídricos e cinco repetições. As avaliações de altura de plantas, diâmetro de caule e número de folhas foram realizadas em seis épocas, enquanto as variáveis condutância estomática e taxa fotossintética foram determinadas em duas épocas. No término do experimento avaliaram-se área foliar, massa seca de folhas, pecíolos, caules e raízes de todas as plantas de pinhão-manso. Os regimes hídricos de 60 e $80 \%$ da capacidade de retenção de água no solo proporcionam as melhores respostas para as variáveis fisiológicas e de crescimento na fase inicial do pinhão-manso. Teores de água disponível em um Latossolo Vermelho distrófico, abaixo de $60 \% \mathrm{e}$ superiores a $80 \%$ da capacidade de retenção de água no solo, induzem sinais de estresse hídrico em plantas jovens de pinhão-manso.
\end{abstract}

Palavras-chave: Jatropha curcas; capacidade de retenção de água no solo; taxa fotossintética.

\section{ABSTRACT}

The objective of this work was to evaluate different water regimes on initial growth and some physiological variables of physic nut (Jatropha curcas L.) in dystrophic Haplustox. The experiment was carried under greenhouse conditions of the Embrapa Western Agriculture, located in Dourados, Mato Grosso do Sul State, Brazil. Treatments corresponded to water regimes of 20,40, 60, 80 e $100 \%$ of the soil water retention capacity. The experimental design adopted was completely randomized with five treatments and five replicates. The evaluations of plants height, stem diameter and number of leaves were performed in six dates, while the variables stomatal conductance and photosynthetic rate were determined in two dates. At the end of experiment were evaluated the leaf area, dry mass of the leaves, petioles, stems and roots of all

1 Engenheira Agrônoma, MSc., Doutoranda em Produção Vegetal pelo Programa de Pós-Graduação em Agronomia, Faculdade de Ciências Agrárias, Universidade Federal da Grande Dourados, Rodovia Dourados - Itahum, km 12, Caixa Postal 533, CEP 79804-970, Dourados (MS), Brasil. nerianepadilha@hotmail.com/ deboraheid@hotmail.com / sibottega@hotmail.com

2 Engenheiro Agrônomo, Dr., Pesquisador A da Embrapa Agropecuária Oeste, BR 163, km 253,6, Caixa Postal 449, CEP 79804-970, Dourados (MS), Brasil. cesar.silva@embrapa.br

3 Engenheiro Agrônomo, Dr., Professor Adjunto do Departamento de Engenharia Agrícola, Universidade Federal de Viçosa, Avenida PH Rolfs, s/n, Centro, CEP 36570-000, Viçosa (MG), Brasil. silviopereira@ufv.br

4 Engenheiro Agrônomo, MSc., Doutorando em Produção Vegetal pelo Programa de Pós-Graduação em Agronomia, Faculdade de Ciências Agrárias, Universidade Federal da Grande Dourados, Rodovia Dourados - Itahum, km 12, Caixa Postal 533, CEP 79804-970, Dourados (MS), Brasil. silvaneto20@yahoo.com.br

5 Bióloga, Dra, Professora Associada da Faculdade de Ciências Agrárias, Universidade Federal da Grande Dourados, Rodovia Dourados - Itahum, km 12, Caixa Postal 533, CEP 79804-970, Dourados (MS), Brasil. silvanascalon@ufgd.edu.br

Recebido para publicação em 8/11/2013 e aceito em 26/08/2014 
plants of physic nut. The water regimes of $60 \%$ and $80 \%$ of the soil water retention capacity provide the best responses to the physiological variables and of growth in the initial phase of physic nut. Available water contents in a dystrophic Haplustox, below of $60 \%$ and superiors the $80 \%$ of the soil water retention capacity induce signs of water stress in young plants of physic nut.

Keywords: Jatropha curcas; soil water retention capacity; photosynthetic rate.

\section{INTRODUÇÃO}

A crescente preocupação mundial com o meio ambiente e a seguridade no fornecimento energético, colocam o biodiesel no centro das atenções e interesses. Diversos países têm buscado em diferentes níveis (agronômico e industrial) o caminho do domínio tecnológico para a produção de biocombustível (ABDALLA et al., 2008).

Reconhecido como mais uma boa opção no leque de plantas oleaginosas para a produção de biodiesel, o pinhão-manso (Jatropha curcas L.) há vários anos recebe atenção de pesquisadores de diversas instituições (ANUÁRIO..., 2007), pois, além de possuir potencial de rendimento de grãos e óleo, permite o cultivo em consórcio com outras culturas de interesse econômico e alimentar (NERY et al., 2009). De acordo com Chagas (2008), além da planta não competir com os alimentos, ela é ecologicamente correta, já que se trata de uma planta de florestamento ou reflorestamento de aéreas degradadas com alta eficiência no sequestro de carbono.

$\mathrm{O}$ pinhão-manso, pertencente à família Euphorbiaceae, é uma planta nativa das Américas, estando disseminada nas regiões tropicais e subtropicais do globo e amplamente distribuída na Ásia, África e Índia. É uma planta perene, podendo ser descrita como um arbusto grande ou árvore de pequeno porte, de crescimento rápido, alcançando uma altura de três a cinco metros, mas podendo atingir 8 metros em condições favoráveis (DIVAKARA et al., 2010). As folhas são decíduas e a primeira inflorescência é cimeira; a planta apresenta abscisão foliar na estação seca, as quais ressurgem logo após as primeiras chuvas (SATURNINO et al., 2005).

Por se tratar de uma espécie agrícola, o desempenho do pinhão-manso é altamente dependente de fatores climáticos, como temperatura, pluviosidade, radiação solar e umidade do solo (LARCHER, 2004). Entre as variáveis fisiológicas mais afetadas pelas condições climáticas está a fotossíntese (DENG et al., 2003), a qual tem recebido especial atenção nos estudos que visam à seleção de espécies e/ou variedades adaptadas aos ambientes adversos, por ser a principal fonte de carbono orgânico e de energia para o crescimento e produção de biomassa das plantas (SANTOS, 2008).

Alguns estudos relacionados com 0 comportamento fisiológico de plantas foram realizados em espécies oleaginosas, buscando compreender, sobretudo, a capacidade fotossintética, condutância estomática e potencial hídrico em condições ambientais controladas e sob condições naturais (NOGUEIRA; SANTOS, 2000; BELTRÃO et al., 2003; ERISMANN; MACHADO; GODOY, 2006; SOUSA, 2006; FREITAS et al., 2011). Porém, estudos sobre a fisiologia do pinhãomanso e a relação água-planta ainda precisam ser aprofundados. Desta forma o conhecimento a respeito do comportamento fisiológico do pinhãomanso em condições de deficiência hídrica no solo e seu consumo de água são de fundamental importância para a domesticação da espécie e para uma maior eficiência no uso da água (ROZA, 2010).

Por ser uma espécie não melhorada, ainda existem poucas informações agronômicas a seu respeito, principalmente em relação ao manejo de irrigação na fase inicial da cultura.

Objetivou-se neste trabalho avaliar a influência de diferentes regimes hídricos no crescimento inicial e em alguns parâmetros fisiológicos do pinhão-manso cultivado em Latossolo Vermelho distrófico.

\section{MATERIAL E MÉTODOS}

No período de abril a junho de 2009 , realizou-se o experimento em casa de vegetação da Embrapa Agropecuária Oeste, em Dourados-MS.

$\mathrm{O}$ solo utilizado, classificado como Latossolo Vermelho distrófico (LVd) detextura média leve ( $16 \%$ de argila) no horizonte superficial, foi coletado no município de Anastácio-MS, na Fazenda Jatiúca, na camada de 0 a $15 \mathrm{~cm}$ de profundidade, foi seco ao ar livre e tamisado em peneira de $4 \mathrm{~mm}$ (5 mesh). Uma subamostra foi submetida às análises químicas e físicas no laboratório de Fertilidade 
e Física do solo da Embrapa Agropecuária Oeste, seguindo metodologia descrita por Embrapa (1997). Os seguintes resultados foram obtidos: $\mathrm{pH}\left(\mathrm{H}_{2} \mathrm{O}\right)$ 5,$5 ; 0,1 \mathrm{cmol}_{\mathrm{c}} \mathrm{dm}^{-3}$ de $\mathrm{Al}^{3+} ; 2 \mathrm{cmol}_{\mathrm{c}} \mathrm{dm}^{-3} \mathrm{de} \mathrm{Ca}^{2+}$;

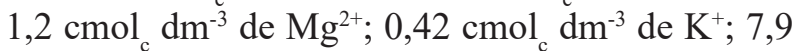
$\mathrm{cmol}_{\mathrm{c}} \mathrm{dm}^{-3}$ de CTC; $11 \mathrm{mg} \mathrm{dm}^{-3}$ de P; $13,3 \mathrm{~g} \mathrm{~kg}^{-1} \mathrm{de}$ MO.; $0,8 \mathrm{mg} \mathrm{dm}^{-3}$ de Cu; 37,7 $\mathrm{mg} \mathrm{dm}^{-3}$ de Fe; 42,3 $\mathrm{mg} \mathrm{dm}{ }^{-3}$ de Mn; 2,9 mg dm${ }^{-3}$ de Zn; $745 \mathrm{~g} \mathrm{~kg}^{-1}$ de areia; $92 \mathrm{~g} \mathrm{~kg}^{-1}$ de silte; $163 \mathrm{~g} \mathrm{~kg}^{-1}$ de argila e 1,32 $\mathrm{g} \mathrm{cm}^{-3}$ de densidade. A capacidade de retenção de água do solo (CRAS) foi determinada pelo método gravimétrico direto, utilizando-se $6,5 \mathrm{~kg}$ de solo por vaso, em quatro repetições. Nestes vasos adicionouse água até ficar saturado, após o escorrimento do excesso sobrou apenas a água retida (solo úmido), e determinou-se a capacidade de retenção de água do solo pela diferença entre as massas do solo úmido e do solo seco.

Posteriormente foi aplicada a mistura de corretivos $\left(\mathrm{CaCO}_{3}\right.$ e $\mathrm{MgCO}_{3}$, em relação molar 4:1), visando à elevação da saturação por bases de $46 \%$ para $65 \%$. A adubação básica constituiu de 50 ; 300 e $30 \mathrm{mg} \mathrm{kg}^{-1}$ de $\mathrm{N}, \mathrm{P}_{2} \mathrm{O}_{5}$ e $\mathrm{K}_{2} \mathrm{O}$ (utilizando-se respectivamente, sulfato de amônio, superfosfato triplo e cloreto de potássio como fontes) e 0,8 ; 0,$08 ; 0,30 ; 0,20 ; 0,01$ e $0,90 \mathrm{mg} \mathrm{kg}^{-1}$ de $\mathrm{B}, \mathrm{Cu}, \mathrm{Fe}$, $\mathrm{Mn}, \mathrm{Mo}$ e $\mathrm{Zn}$, respectivamente (usando-se ácido bórico, sulfato de cobre, sulfato ferroso, sulfato de manganês, ácido molíbdico e sulfato de zinco). Os macronutrientes e micronutrientes foram misturados ao solo por meio de betoneira.

Após a adição dos corretivos de acidez e fertilizantes, o solo foi colocado nos vasos e mantido em incubação por um período de 15 dias. Durante este período todos os vasos foram mantidos a $80 \%$ da capacidade de retenção de água do solo (CRAS).

$\mathrm{O}$ delineamento experimental adotado foi o inteiramente casualizado com cinco tratamentos (regimes hídricos) e cinco repetições, nos quais cada repetição correspondeu a uma planta cultivada em um vaso. As avaliações de altura de plantas, diâmetro de caule e número de folhas foram realizadas em seis épocas. Já variáveis como condutância estomática e fotossíntese foram determinadas em duas épocas.

Os tratamentos corresponderam aos regimes hídricos de 20,40,60, 80 e $100 \%$ da CRAS. Em seguida ao ajuste da umidade do solo, de acordo com cada tratamento (Tabela 1), realizou-se a semeadura de 4 sementes escarificadas (escarificação mecânica) por vaso, tendo sido feito o desbaste 3 dias após a emergência (DAE), deixandose uma planta por vaso.
TABELA 1: Regimes hídricos e umidade do solo correspondente a cada tratamento.

TABLE 1: Water regimes and soil moisture corresponding to each treatment.

\begin{tabular}{cc}
\hline Regimes hídricos & Umidade (\%) \\
\hline $20 \%$ CRAS & 5,62 \\
$40 \%$ CRAS & 11,24 \\
$60 \%$ CRAS & 18,87 \\
$80 \%$ CRAS & 22,50 \\
$100 \%$ CRAS & 28,11 \\
\hline
\end{tabular}

Em que: CRAS $=$ Capacidade de retenção de água no solo.

Até 8 DAE, os vasos foram pesados a cada dois dias e o volume de água evapotranspirado reposto de acordo com cada um dos regimes hídricos. Dos 9 aos 42 DAE, todos os vasos foram pesados diariamente. Semanalmente foram realizados rodízio dos vasos na bancada.

Fez-se adubação de cobertura aos 15 DAE, com aplicação de 50 e $30 \mathrm{mg} \mathrm{kg}^{-1}$ de $\mathrm{N}$ e K (utilizando-se respectivamente, sulfato de amônio e cloreto de potássio como fontes). Os nutrientes foram misturados à água de irrigação.

As avaliações das variáveis altura de plantas (usando-se uma trena), diâmetro de caule (medidos com auxílio de paquímetro) e número de folhas foram realizadas aos $7,14,21,28,35$ e 42 DAE. Já a condutância estomática e a taxa fotossintética (medidos pelo aparelho LCi Analyser Serial $\mathrm{N}^{\circ} 32057$ ) foram realizadas aos 14 e 28 DAE.

Aos 42 DAE foram coletadas as cinco plantas de cada tratamento para avaliação da área foliar (utilizando-se o integrador eletrônico LI 3000), posteriormente, as folhas, pecíolos, caules e raízes de cada tratamento foram colocados em estufa de circulação forçada a $65^{\circ} \mathrm{C}$ até peso constante para a determinação da massa seca.

As variáveis taxa fotossintética e condutância estomática foram submetidas à análise de variância, e a comparação entre as médias foi feita pelo teste de Tukey a $5 \%$ de probabilidade, com auxílio do programa computacional Saeg (2007). Os efeitos de regimes hídricos foram avaliados por meio de ajuste de modelo de regressão.

\section{RESULTADOS E DISCUSSÃO}

No tratamento hídrico de $20 \%$ da CRAS houve um crescimento limitado das plantas, enquanto os tratamentos hídricos de 40,60, 80 e $100 \%$ de CRAS apresentaram crescimento linear ao 
longo das avaliações. Os tratamentos de 60 e 100\% da CRAS apresentaram os maiores valores para a variável altura de plantas. As plantas submetidas ao regime hídrico de $40 \%$ da CRAS toleraram a baixa quantidade de água disponível, mas tiveram baixa taxa de crescimento. A variável diâmetro de caule apresentou um crescimento linear em função do tempo de avaliação, a exceção no tratamento de $20 \%$ da CRAS, no qual se ajustou uma função exponencial para essa variável. Os regimes hídricos de 60 e $80 \%$ da CRAS proporcionaram os maiores diâmetros, ao passo que os tratamentos de $40 \mathrm{e}$ $100 \%$ resultaram valores intermediários e $20 \%$ da CRAS o menor diâmetro. Em condições de baixa umidade do solo ocorreu uma diminuição no ritmo de crescimento de plantas de pinhão-manso em altura e diâmetro de caule, em relação aos outros tratamentos hídricos (Figuras 1A e 1B). De acordo com Tognon (2010), a redução do crescimento é um dos principais sintomas de deficit hídrico, estando a água diretamente ligada à expansão e elongação celular, fazendo com que a sua restrição ocasione

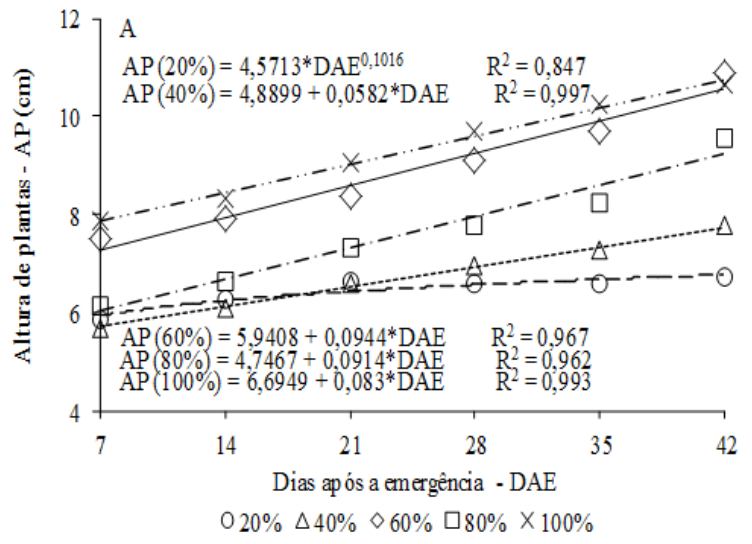

uma paralisação nesses processos fisiológicos da planta, uma vez que as células só crescem quando estão túrgidas.

O número de folhas por planta de pinhãomanso aumentou linearmente em função do tempo de avaliação, nos regimes hídricos de 40, 60, 80 e $100 \%$ da CRAS. Por outro lado, o regime de $20 \%$ da CRAS apresentou um ajuste quadrático, aumentando o número de folhas dos 7 aos $21 \mathrm{DAE}$, e posteriormente diminuiu até os $42 \mathrm{DAE}$, em função da senescência das folhas, causada pelo deficit hídrico (Figura 1C). De acordo com Smit e Singels (2006), o menor número de folhas no tratamento $20 \%$ da CRAS é decorrente da intensidade do estresse hídrico, que causa acentuada senescência foliar e restrição ao surgimento de novas folhas. Segundo Inman-Bamber et al. (2008), essa redução do número de folhas é uma estratégia para diminuir a superfície transpirante e o gasto metabólico para a manutenção dos tecidos.

Aaltura das plantas aos $42 \mathrm{DAE}$ apresentou uma resposta exponencial, sendo em função do

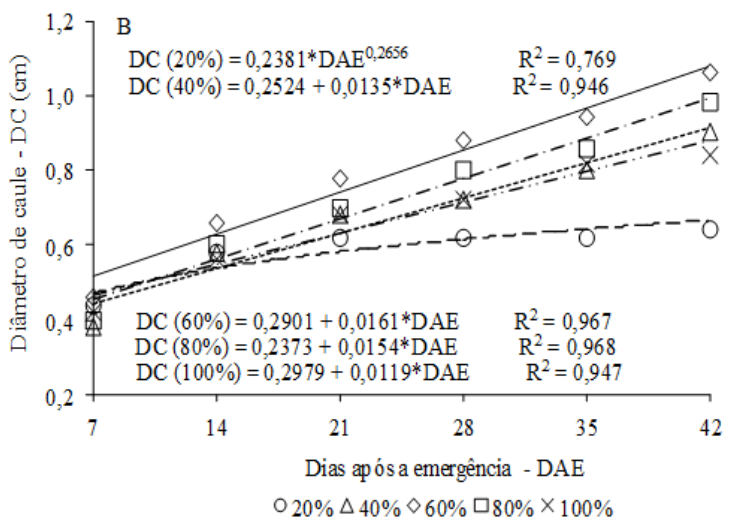

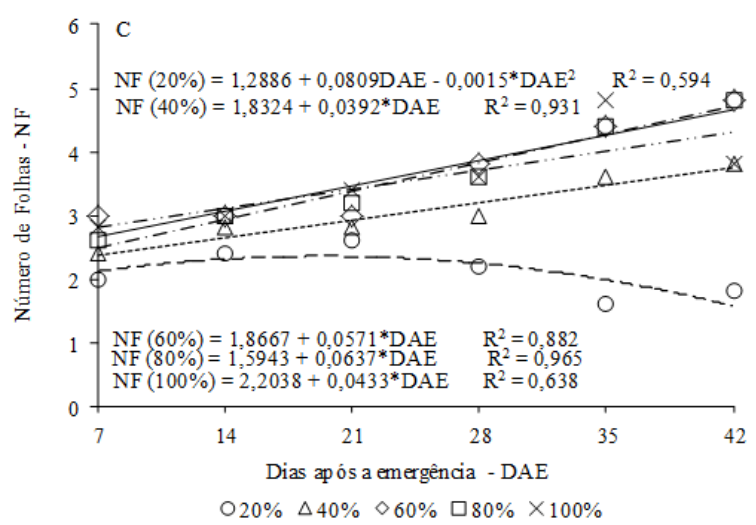

FIGURA 1: Crescimento de plantas de pinhão-manso submetidas a diferentes regimes hídricos - (A) altura de plantas, (B) diâmetro de caule, (C) número de folhas, em Dourados-MS, 2009.

FIGURE 1: Growth of physic nut plants submitted to different water regimes - (A) plants height, (B) stem diameter, (C) number of leaves, in Dourados-MS, 2009. 
regime hídrico, que quanto maior a disponibilidade hídrica, maior foi o crescimento da planta, o que permite destacar um crescimento $61,7 \%$ superior no tratamento com máxima disponibilidade hídrica em relação ao de $20 \%$ da CRAS. Aos 42 DAE, o diâmetro de caule apresentou uma resposta quadrática ao regime hídrico, seu ponto máximo foi obtido com $61,75 \%$ da CRAS com diâmetro de 0,98 $\mathrm{cm}$ (Figuras 2A e 2B).

Com a umidade mantida em $20 \%$ da CRAS, ocorreu uma diminuição do ritmo de crescimento em altura e diâmetro de caule, em relação aos outros tratamentos. A deficiência hídrica afeta o crescimento das plantas porque reduz a diferenciação celular, devido à redução na turgescência da célula (OLIVA et al., 1989; CAIRO, 1995; NOGUEIRA; ALBUQUERQUE; SILVA, 2005), o que resulta na diminuição do desenvolvimento da área foliar e consequentemente afeta a produção e a translocação de fotoassimilados para as novas áreas de crescimento (LUDLOW; MUCHOW, 1990; LARCHER, 2004).
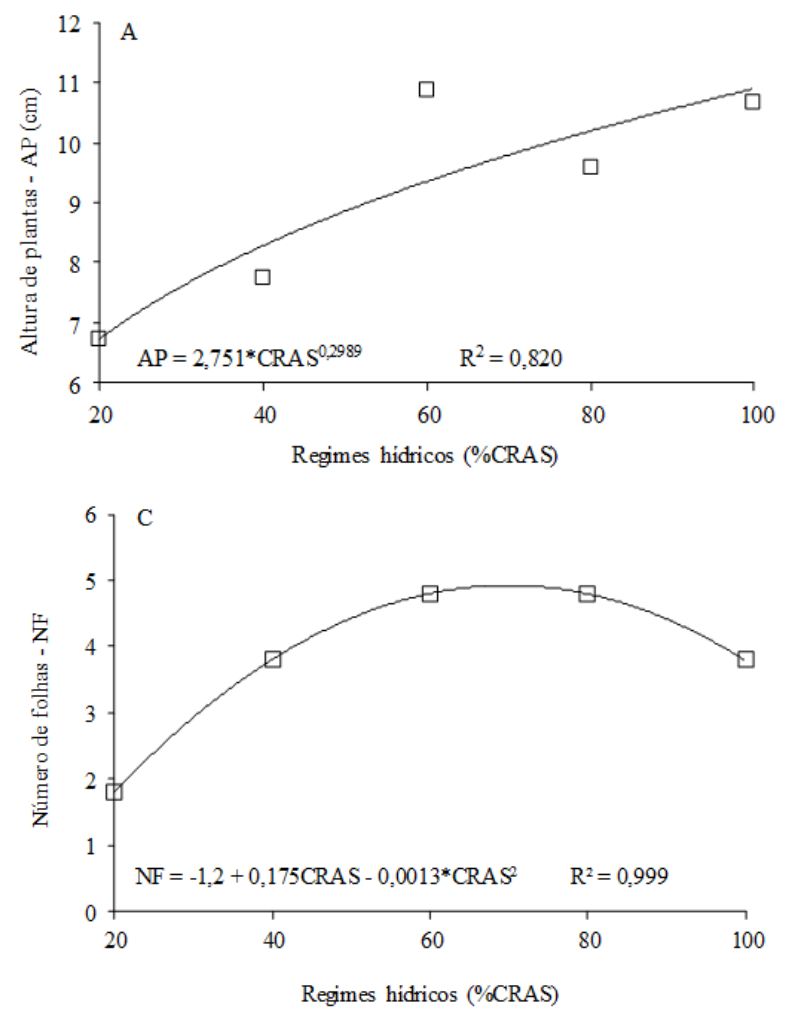

A variável número de folhas aos $42 \mathrm{DAE}$ foi ajustada a uma função quadrática em relação ao regime hídrico, no qual o ponto máximo foi a $67 \%$ da CRAS, contendo 4,7 folhas, e depois passou a decrescer. Os tratamentos de 20, 40, 60, 80 e $100 \%$ da CRAS apresentaram uma redução do número de folhas de 163,$5 ; 26,1 ; 1,52 ; 4,7$ e $42,1 \%$; respectivamente, quando comparados ao tratamento de $67 \%$ da CRAS. Para a variável área foliar aos 42 DAE foi ajustada uma função quadrática em relação ao regime hídrico, com ponto máximo de $69 \%$ da CRAS, com área foliar a $594 \mathrm{~cm}^{2}$. Os regimes hídricos menores e maiores que $67 \%$ e $69 \%$ da CRAS proporcionaram uma queda nos valores de número de folhas e área foliar, respectivamente, devido ao estresse hídrico por deficit e excesso de água (Figuras 2C e 2D).

De acordo com Díaz-López et al. (2012), em condições de menor disponibilidade de água no solo, ocorre menor expansão das folhas, maior senescência e abscisão foliar, resultando na redução do número de folhas e da área foliar, como forma de
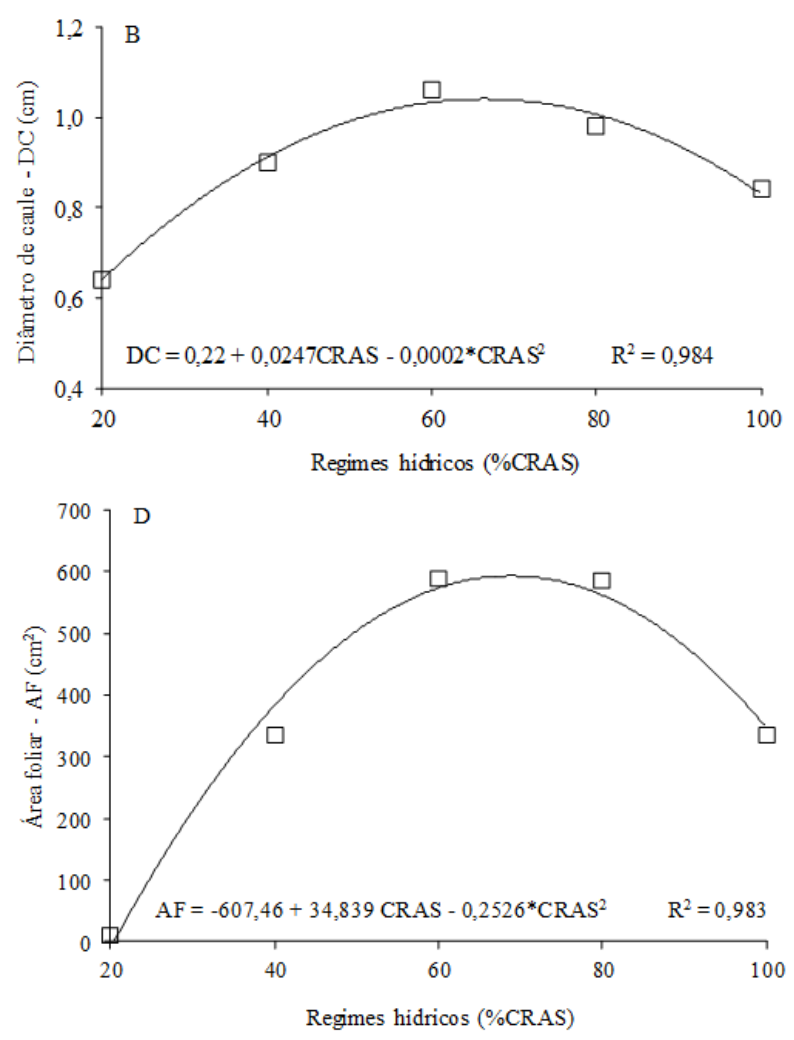

FIGURA 2: Plantas de pinhão-manso, aos 42 dias após a emergência (DAE), submetidas a diferentes regimes hídricos - (A) altura de plantas, (B) diâmetro de caule, (C) número de folhas, (D) área foliar, em Dourados-MS, 2009.

FIGURE 2: Physic nut plants to 42 days after emergency submitted to different water regimes - (A) plants height, (B) stem diameter, (C) number of leaves, (D) leaf area, in Dourados-MS, 2009. 
diminuir perdas de água por transpiração. Segundo Tognon (2010), no início do estresse algumas folhas entram em processo de senescência, fato este observado pelo amarelecimento das mesmas. $\mathrm{O}$ deficit hídrico aumenta a senescência foliar, isso ocorre porque o solo seco não pode fornecer nitrogênio suficiente para suprir as necessidades de crescimento da planta, então o nitrogênio do interior do vegetal é retranslocado das folhas mais velhas para os pontos de crescimento; entretanto, a intensidade da senescência depende da quantidade de nitrogênio no solo, das reservas de nitrogênio na planta e da demanda de nitrogênio dos pontos de crescimento (WOLFE et al., 1988).

Segundo Arruda e Calbo (2004), o excesso de água também causa distúrbios na planta, como queda das folhas e redução na expansão foliar. Taiz e Zeiger (2009) explicam que o excesso de água ocasiona a falta de oxigênio para as raízes, levando ao aumento da produção do ACC (1-aminociclopropano-1-ácido carboxílico). O ACC é translocado da raiz para a parte aérea e na presença de oxigênio é convertido em etileno. O etileno pode levar à redução da emissão, abscisão e senescência foliar, consequentemente diminuindo o número de folhas e a área foliar.

Houve diferença significativa isoladamente e entre tratamentos e tempo em que foram realizadas as avaliações de taxa fotossintética e condutância estomática (Tabela 2).

A menor taxa fotossintética aos 14 DAE, em plantas de pinhão-manso foi obtida pelo regime hídrico de $20 \%$ da CRAS. Já nos regimes de 40 , 60,80 e $100 \%$ da CRAS, não houve diferença significativa. Aos 28 DAE ocorreu um aumento na taxa fotossintética em todos os tratamentos, exceto no de $20 \%$ da CRAS, que apresentou um decréscimo. As maiores taxas fotossintéticas foram obtidas pelos tratamentos hídricos de 60 e $80 \%$ da CRAS. A taxa fotossintética aos 28 DAE foram 319 e $356 \%$ superiores nos tratamentos de 60 e $80 \%$ da
CRAS, respectivamente, quando comparada ao de $20 \%$ da CRAS. O aumento na taxa fotossintética nos tratamentos de 60 e $80 \%$ da CRAS ocorreu principalmente pelo aumento da disponibilidade de água (Figura 3A).

Aos 14 DAE, a condutância estomática não diferiu significativamente entre os tratamentos, mas aos 28 DAE os regimes hídricos de 20 e $80 \%$ CRAS resultaram no menor e maior valor de condutância estomática, respectivamente (Figura 3B).

De acordo com Jones (1985), o deficit hídrico afeta a bioquímica, a fisiologia, a morfologia e os processos de desenvolvimento das plantas, reduzindo a fotossíntese de três maneiras: pela redução na área foliar disponível para interceptar a radiação solar, pela redução da difusão do $\mathrm{CO}_{2}$ para dentro da folha e pela redução da habilidade dos cloroplastos para fixar o $\mathrm{CO}_{2}$ que neles penetra.

Quando ocorre deficit hídrico, um dos primeiros acontecimentos na planta é o fechamento estomático (diminuindo a condutância estomática), em resposta ocorre um declínio da turgescência da folha e/ou do seu potencial hídrico (YORDANOV; VELIKOVA; TSONEV, 2003), ou, ainda, em resposta há um aumento da concentração de ácido abscísico no fluxo transpiratório (CHAVES; MARROCO; PEREIRA, 2003). O ácido abscísico estimula o fechamento dos estômatos; desde que sua síntese seja estimulada pela deficiência hídrica. Então, um ligeiro ressecamento do solo, mesmo que não afete as relações hídricas da parte aérea, causa aumento na concentração de ácido abscísico no xilema, provavelmente produzido na coifa das raízes, levando assim ao fechamento estomático (SANTOS; CARLESSO, 1998; INMANBAMBER; SMITH, 2005). Com o fechamento dos estômatos das folhas, a afluência de $\mathrm{CO}_{2}$ ao mesmo tempo também diminui, resultando na redução da taxa fotossintética (LAWLOR; UPRETY, 1993).

O tratamento de $100 \%$ da CRAS aos 28 DAE apresentou uma redução da taxa fotossintética

TABELA 2: Análise de variância para taxa fotossintética e condutância estomática de folhas de pinhãomanso submetido a diferentes regimes hídricos, em Dourados-MS, 2009.

TABLE 2: Analysis of variance for photosynthetic rate and stomatal conductance of physic nut leaves submitted to different water regimes, in Dourados-MS, 2009.

\begin{tabular}{ccc}
\hline Fatores & Taxa fotossintética & Condutância estomática \\
\hline & $\mu \mathrm{mol} \mathrm{m}^{-2} \mathrm{~s}^{-1}$ & $\mathrm{~mol} \mathrm{~m}^{-2} \mathrm{~s}^{-1}$ \\
F (Regimes hídrico) & $69,54^{*}$ & $33,40^{*}$ \\
CV $(\%)$ & 14,44 & 26,55 \\
\hline
\end{tabular}

Em que: * = significativo a 5\% de probabilidade; $\mathrm{CV}=$ coeficiente de variação. 


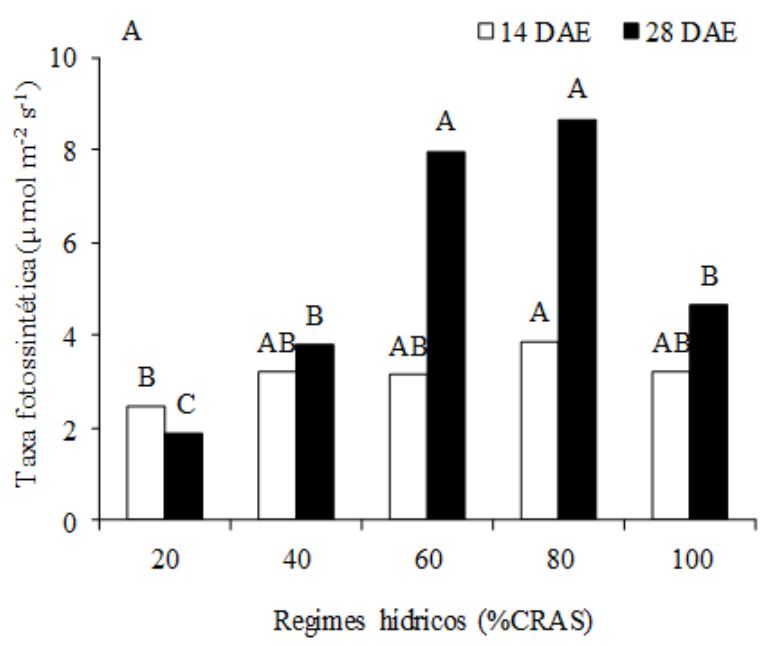

FIGURA 3: Variáveis fisiológicas de plantas de pinhão-manso submetidas a diferentes regimes hídricos - (A) taxa fotossintética, (B) condutância estomática, em Dourados-MS, 2009. Médias com mesma letra não diferem entre si pelo teste de Tukey e teste $\mathrm{F}(\mathrm{p}<0,05)$.

FIGURE 3: Physiological Variables of physic nut plants submitted to different water regimes - (A) photosynthetic rate, (B) stomatal conductance, in Dourados-MS, 2009. Means with the same letter are not significantly different by Tukey's test and F test $(\mathrm{p}<0.05)$.

e da condutância estomática em relação aos regimes hídricos de 60 e $80 \%$ da CRAS (Figura 3). A redução da condutância estomática pode ter ocorrido devido ao excesso de água (estresse anaeróbico). De acordo com Fernández (2006), plantas sob condições de estresse anaeróbico possuem uma limitação nas trocas gasosas pelo fechamento estomático. A baixa disponibilidade de oxigênio pode afetar a condutância estomática, diminuindo a perda de água pela transpiração e diminuindo a taxa fotossintética.

As massas secas de folhas, pecíolos, raízes e massa seca total apresentaram um ajuste quadrático em relação ao regime hídrico, cujos maiores valores de massas secas foram obtidos nos tratamentos de $72,11 \%, 73,50 \%, 81,39 \%$ e $74,65 \%$ da CRAS, respectivamente. Somente a massa seca de caule não apresentou ajuste a nenhuma função matemática, pois não houve efeito dos regimes hídricos nessa variável analisada. O menor acúmulo de massa seca foi obtido com o regime de $20 \%$ da CRAS (Figura 4).

Os baixos valores de massas secas expressos nos tratamentos de $20 \%$ da CRAS são devido ao primeiro efeito biológico significante do estresse hídrico, que é a redução de turgor que ocasiona paralisação do crescimento das plantas, fato expresso na redução da massa seca de folhas, caules, pecíolos e raízes (TAIZ; ZEIGER, 2004).

A massa seca de folhas de pinhão-manso foi afetada nos tratamentos abaixo de $60 \%$ da CRAS e acima de $80 \%$ da CRAS (Figura 4), devido, principalmente, à diminuição do número de folhas (Figura 2C) e diminuição da área foliar (Figura 2D), sintomas estes causados por falta (tratamentos

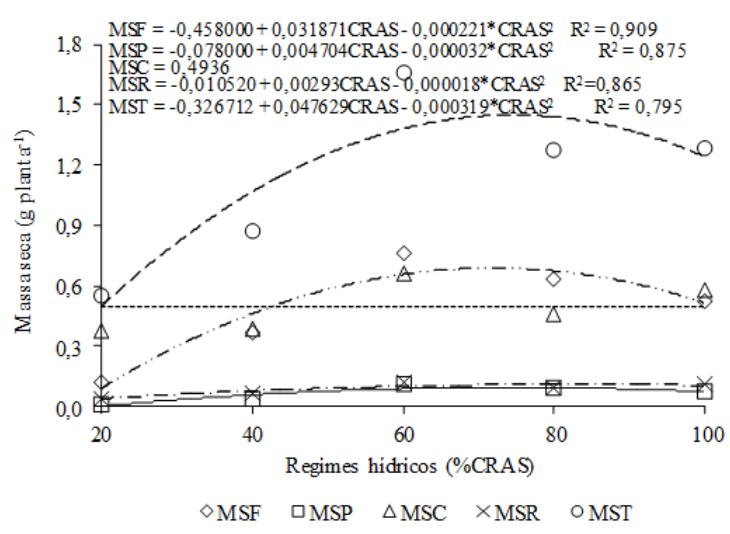

FIGURA 4: Massa seca de folhas (MSF), pecíolo (MSP), caule (MSC), raiz (MSR) e massa seca total (MST) de plantas de pinhão-manso submetidas a diferentes regimes hídricos, em Dourados-MS, 2009.

FIGURE 4: Leaf dry mass, petioles, stems, roots and total of physic nut plants submitted to different water regimes, in DouradosMS, 2009. 
abaixo de $60 \%$ da CRAS) e excesso de água (tratamento acima de $80 \%$ da CRAS).

\section{CONCLUSÕES}

Os resultados obtidos nesse trabalho permitem concluir que:

1. Os regimes hídricos de 60 e $80 \%$ da capacidade de retenção de água no solo proporcionam as melhores respostas para parâmetros fisiológicos e de crescimento na fase inicial do pinhão-manso em Latossolo Vermelho distrófico;

2. Teores de água disponível em um Latossolo Vermelho distrófico, abaixo de $60 \%$ e superiores a $80 \%$ da capacidade de retenção de água no solo, induzem sinais de estresse hídrico em plantas jovens de pinhão-manso.

\section{AGRADECIMENTOS}

Ao MCT/FINEP (Convênio $\mathrm{n}^{\circ}$ 01.10.0015.00), pelo apoio financeiro a esta pesquisa, à EMBRAPA por disponibilizar sua estrutura para a realização do trabalho e à Coordenação de Aperfeiçoamento de Pessoal de Nível Superior (CAPES), pela concessão de bolsa de estudo.

\section{REFERÊNCIAS BIBLIOGRÁFICAS}

ANUÁRIO BRASILEIRO DE AGROENERGIA. Pinhão-manso. Santa Cruz do Sul: Gazeta, 2007. $520 \mathrm{p}$.

ABDALLA, A. B. et al. Utilização de subprodutos da indústria de biodiesel na alimentação de ruminantes. Revista Brasileira de Zootecnia, Viçosa, v. 37, p. 260-268, 2008.

ARRUDA, G. M. T.; CALBO, M. E. R. Efeitos da inundação no crescimento, trocas gasosas e porosidade radicular da carnaúba (Copernicia prunifera (Mill.) H.E. Moore). Acta Botanica Brasilica, Belo Horizonte, v. 18, p. 219-224, 2004.

BELTRÃO, N. E. M. et al. Fisiologia da mamoneira, cultivar BRS 149 nordestina, na fase inicial de crescimento, submetida a estresse hídrico. Revista Brasileira de Oleaginosas e Fibrosas, Campina Grande, v. 7, p. 659-664, 2003.

CAIRO, P. A. R. Curso básico de relações hídricas de plantas. Vitória da Conquista: UESB, 1995. $32 \mathrm{p}$.

CHAGAS, P. D. Esperança Nacional. Revista do Biodiselbr, Curitiba, v. 1, p. 24-34, 2008.

CHAVES, M. M.; MAROCO, J. P.; PEREIRA, J.
S. Understanding plant responses to drought - from genes to the whole plant. Functional Plant Biology, Austrália, v. 30, p. 239-264, 2003.

DENG, X. et al. A comparison of photosynthetic apparatus of the detached leaves of the resurrection plant Boea hygrometrica with its non-tolerant relative Chirita hererotrichia in response to dehydration and rehydration. Plant Science, Amsterdã, v. 165, p. 851-861, 2003.

DÍAZ-LÓPEZ, L. et al. Jatropha curcas seedlings show a water conservation strategy under drought conditions based on decreasing leaf growth and stomatal conductance. Agricutural Water Management, Amsterdã, v. 105, p. 48-56, 2012. DIVAKARA, B. N. et al. Biology and genetic improvement of Jatropha curcas L.: A review. Applied Energy, Amsterdã, v. 87, p. 732-742, 2010. EMBRAPA. Manual de métodos de análise de solo. Rio de janeiro: EMBRAPA-Centro Nacional de Pesquisa de Solos, 1997. 212 p.

ERISMANN, N. M.; MACHADO, E. C.; GODOY, I. J. Capacidade fotossintética de genótipos de amendoim em ambiente natural e controlado. Pesquisa Agropecuária Brasileira, Brasília, v. 41, p. 1099-1108, 2006.

FERNÁNDEZ, M. D. Changes in photosynthesis and fluorescence in response to flooding in emerged and submerged leaves of Pouteria orinocoensis. Photosynthetica, República Checa, v. 44, p. 32-38, 2006.

FREITAS, C. A. S. et al. Produção de matéria seca e trocas gasosas em cultivares de mamoneira sob níveis de irrigação. Revista Brasileira de Engenharia Agrícola e Ambiental, Campina Grande, v. 15, p. 1168-1174, 2011.

INMAN-BAMBER, N. G. et al. Increasing sucrose accumulation in sugarcane by manipulating leaf extension and photosynthesis with irrigation. Australian Journal of Agricultural Research, Austrália, v. 59, p. 13-26, 2008.

; SMITH, D. M. Water relations in sugarcane and response to water deficits. Field Crops Research, Amsterdã, v. 92, p. 185-202, 2005.

JONES, C. A. C4 Grasses and cereals: growth, development and stress response. New York: John Wiley \& Sons, 1985. 419 p.

LARCHER, W. Ecofisiologia vegetal. São Carlos: Rima, 2004. $531 \mathrm{p}$.

LAWLOR, D. W.; UPRETY, D. C. Effects of water stress on photosynthesis of crops and the biochemical mechanism. In: ABROL, Y. P.; MOHANTY, P.; GOVINDJEE (Eds.). Photosynthesis: 
photoreactions to plant productivity. New York: Springer, 1993. p. 419-449.

LUDLOW, M. M.; MUCHOW, R. C. A critical evaluation of traits for improving crop yields in water-limited environments. Advances in Agronomy, São Diego, v. 43, p. 107-153, 1990. NERY, A. R. et al. Crescimento do pinhãomanso irrigado com águas salinas em ambiente protegido. Revista Brasileira de Engenharia Agrícola e Ambiental, Campina Grande, v. 13, p. 551-558, 2009.

NOGUEIRA, R. J. M. C.; ALBUQUERQUE, M. B.; SILVA, E. C. Aspectos ecofisiológicos da tolerância à seca em plantas da caatinga. In: NOGUEIRA, R. J. M. C. et al. Estresses ambientais: danos e benefícios em plantas. Recife: Universidade Federal de Pernambuco, 2005. p. 22-31.

SANTOS, R. C. Alterações fisiológicas no amendoim submetido ao estresse hídrico. Revista Brasileira de Engenharia Agrícola e Ambiental, Campina Grande, v. 4, p. 41-45, 2000.

OLIVA, M. A. et al. Seca de ponteiros em Eucalyptus camaldulensis Dehn em relação a estresse hídrico e nutrição mineral. Revista Árvore, Viçosa, v. 13, p. 19-33, 1989.

ROZA, F. A. Alterações morfofisiológicas e eficiência de uso da água em plantas de Jatropha curcas L. submetidas à deficiência hídrica. 2010. 67 f. Dissertação (Mestrado) - Universidade Estadual de Santa Cruz, Ilhéus, 2010.

SAEG. Sistema para Análises Estatísticas, Versão 9.1. Viçosa: Fundação Arthur Bernardes, 2007. SANTOS, C. M. Fenologia e capacidade fotossintética do pinhão-manso (Jatropha curcas L.) em diferentes épocas do ano no estado de
Alagoas. 2008. 67 f. Dissertação (Mestrado) Universidade Federal de Alagoas, Rio Largo, 2008. SANTOS, R. F.; CARLESSO, R. Déficit hídrico e os processos morfológicos e fisiológicos das plantas. Revista Brasileira de Engenharia Agrícola e Ambiental, Campina Grande, v. 2, p. 287-294, 1998.

SATURNINO, H. M. et al. Cultura do pinhão-manso (Jatropha curcas L.). Informe Agropecuário, Belo Horizonte, v. 26, p. 44-78, 2005.

SMIT, M. A.; SINGELS, A. The response of sugarcane canopy development to water stress. Field Crops Research, Amsterdã, v. 98, p. 91-97, 2006.

SOUSA, S. M. Comportamento sazonal de sete genótipos de coqueiro (Cocos nucifera $\mathrm{L}$.) nas condições ecológicas de Mojú no Estado do Pará. 2006. 68 f. Dissertação (Mestrado) - Universidade Federal Rural da Amazônia, Belém, 2006.

TAIZ, L.; ZEIGER, E. Fisiologia vegetal. Porto Alegre: Artmed, 2004. 613 p. (Artmed. Fisiologia vegetal, 3).

Fisiologia vegetal. Porto Alegre: Artmed, 2009. 848 p. (Artmed. Fisiologia vegetal, 4).

TOGNON, G. B. Potencial ornamental, propagação, rendimento de óleos essenciais e resposta à deficiência hídrica de ipoméias. 2010. 133 f. Dissertação (Mestrado) - Universidade de Passo Fundo, Passo Fundo, 2010.

WOLFE, D. W. et al. Interactive water and nitrogen effects on senescence of maize: I. Leaf area duration, nitrogen distribution, and yield. Agronomy Journal, Madison, v. 80, p. 859-864, 1988.

YORDANOV, I.; VELIKOVA, V.; TSONEV, T. Plant responses to drought and stress tolerance. Bulgarian Journal of Plant Physiology, Sofia, special issue, p. 187-206, 2003. 